\title{
Absence of single-locus complementary sex determination in the braconid wasps Asobara tabida and Alysia manducator
}

\author{
LEO W. BEUKEBOOM*, JACINTHA ELLERS \& JACOUES J. M. VAN ALPHEN \\ Institute of Evolutionary and Ecological Sciences, University of Leiden, PO Box 9516, NL-2300 RA Leiden, \\ The Netherlands
}

\begin{abstract}
In species with single-locus complementary sex determination (sl-CSD), sex is determined by multiple alleles at a single locus. In the haplodiploid Hymenoptera, sl-CSD results in females, if individuals are heterozygous at the sex locus, and in males, if individuals are hemizygous (haploid males) or homozygous (diploid males). Several hymenopteran species have been shown to have sl-CSD, but in several others sl-CSD is absent and the phylogenetic distribution remains unclear. In the family Braconidae, all four species tested so far were shown to possess sl-CSD. In this study, inbreeding experiments were used to test for the presence of sl-CSD in two species belonging to a subfamily of the Braconidae, Asobara tabida and Alysia manducator (Alysiinae). In both species inbreeding experiments showed no difference in brood size or sex ratio compared to the (outbred) control group. Furthermore, the sex ratios found in the inbreeding treatment differed significantly from the sex ratios expected under sl-CSD. Therefore, we conclude that sl-CSD is absent in these species. This study is the first to show the lack of sl-CSD in species of the Braconidae family and that hymenopteran sex-determining mechanisms can vary, even within a family.
\end{abstract}

Keywords: Alysiinae, arrhenotoky, complementary sex determination, diploid male, haplodiploidy, Hymenoptera.

\section{Introduction}

A variety of sex-determining mechanisms is known from insects and includes male and female heterogamety, haplodiploidy, paternal genome loss and systems with X chromosome elimination (Metz, 1938; HughesSchrader, 1948; Crozier, 1971; Bull, 1983; Nur, 1989; Sanchez \& Perondini, 1999). Although systems may appear similar at the chromosomal level, the underlying nature and molecular organization of the sex-determining genes may be very different; for example, both in the fruitfly Drosophila melanogaster and the nematode Caenorhabditis elegans sex is determined by the ratio of $\mathrm{X}$ chromosomes to autosomes, but there is little conservation among the genes involved (Hodgkin, 1990). Sometimes different systems of sex determination have been found in a single species; for example, in the house fly Musca domestica, male-determining genes can

Correspondence: Leo Beukeboom, Institute of Evolutionary and Ecological Sciences, University of Leiden, PO Box 9516, NL-2300 RA Leiden, The Netherlands. Tel: 3171 5274839, Fax: 3171 5274900, E-mail: beukeboom@rulsfb.leidenuniv.nl

*Correspondence. E-mail: beukeboom@rulsfb.leidenuniv.nl be present on the $\mathrm{Y}$ chromosome and each of the autosomes (Dübendorfer et al., 1992). Nevertheless, it has been argued that all sex-determining mechanisms in insects conform to a single organizational scheme (Nöthiger \& Steinmann-Zwicky, 1985), but to date too few systems have been studied in sufficient detail to verify this proposition.

At least two mechanisms of sex determination occur among Hymenoptera. Whiting $(1939,1943)$ proposed single-locus complementary sex determination (sl-CSD) based on his studies of Bracon. Sex is determined by multiple alleles at a single locus; homozygosity leads to males and heterozygosity to females. All Hymenoptera (over 200000 species of ants, bees and wasps) are haplodiploid. Arrhenotoky is the most prevalent mode of reproduction, i.e. unfertilized eggs develop into haploid, hemizygous males and fertilized eggs into heterozygous, diploid females. Homozygous diploid males can arise through inbreeding, and controlled inbred crosses are typically used to detect CSD (Whiting, 1943; Crozier, 1971; Cook, 1993a,b). The estimated number of alleles at the sex locus typically ranges from 10 to 20 (Cook \& Crozier, 1995), but can be as high as 
86 in fireants (Ross et al., 1993). sl-CSD is clearly absent in some Hymenoptera. Several models have been proposed to explain sex determination in such species, including multilocus complementary sex determination (ml-CSD, Crozier, 1971), but there is very little evidence to support any of them (Cook, 1993b; Beukeboom, 1995).

The phylogenetic distribution of sl-CSD within the Hymenoptera is still unclear. sl-CSD has now been shown to occur in approximately 40 species belonging to all major suborders including ants and bees (Aculeata), sawflies (Symphyta) and parasitic wasps (Parasitica) (reviewed in Stouthamer et al., 1992; Cook, 1993b; Periquet et al., 1993). It appears to be completely absent from the superfamily Chalcidoidea (Cook, 1993b). Moreover, it has been suggested that CSD is the ancestral mode of sex determination within Hymenoptera (Schmieder \& Whiting, 1947; Crozier, 1977; Cook, 1993b), but this remains doubtful until more species have been tested for CSD. Among the large family Braconidae, all four previously tested members were shown to have sl-CSD, i.e. three species of Braconinae [Bracon brevicornis (Speicher \& Speicher, 1940), B. hebetor (= Habrobracon juglandis) (Whiting \& Whiting, 1925; Whiting, 1943) and B. serinopae (Clark \& Rubin, 1961)] and one Microgasterinae [Microplitis croceipes (Steiner \& Teig, 1989)].

A CSD mechanism of sex determination is likely to be absent in a number of species because it is in conflict with their population biology or reproductive mechanism. Selection against CSD is expected under a population structure characterized by high inbreeding imposing a strong genetic load on a population because diploid males are typically sterile and less viable (Crozier, 1977; Cook \& Crozier, 1995). Many parasitic wasp species including several chalcidoids (Hardy, 1994) exhibit strong natural inbreeding and diploid males apparently never occur, although few studies have empirically shown the absence of diploid males after prolonged inbreeding (Skinner \& Werren, 1980; Cook, 1993a; reviewed in Cook, 1993b). Thelytoky is a less common mode of reproduction among Hymenoptera and involves parthenogenetic reproduction of females in the absence of males. Certain forms of thelytokous reproduction lead to complete homozygosity (Crozier, 1975; Suomalainen et al., 1987) and are therefore inconsistent with CSD (reviewed by Cook, 1993b).

Species with a CSD mode of sex determination may be difficult to maintain in culture because of a diminishing number of sex alleles and a concomitant increase in (sterile) diploid males (Stouthamer et al., 1992). Because some cultures of braconid wasp species apparently thrived for many years, these species were believed to lack sl-CSD but this was never investigated experimentally. In this paper, we report inbreeding experi- ments which show the absence of sl-CSD in two braconid species belonging to the subfamily Alysiinae, Asobara tabida and Alysia manducator. These species are parasitoids of larvae of Diptera in ephemeral, patchily distributed microhabitats. They often experience inbreeding and thus are candidates for a sex-determining mechanism different from sl-CSD. We test for the presence of sl-CSD by comparing: (i) actual brood sizes and sex ratios of inbred crosses with those of control crosses; and (ii) sex ratios of inbred crosses with the expected sex ratio under sl-CSD as estimated from the control crosses. Because there is some recent evidence that the expression of CSD is temperature sensitive (Butcher et al., 1998), we conducted our experiments at two temperatures, one at which the cultures are normally maintained and the other a maximum at which the species can develop.

\section{Materials and methods}

\section{Biology of Asobara tabida and Alysia manducator}

Alysiinae are solitary endoparasites of several cyclorrhaphous Diptera (Gauld \& Bolton, 1996). Asobara tabida attacks larvae of Drosophila subobscura and D. melanogaster in fermenting substrates. This species has a Holarctic distribution, and is known in Europe from Scandinavia to the Mediterranean. The A. tabida strain used here was established in the summer of 1996 from approximately 15 wild-caught $A$. tabida females from the vicinity of Leiden, the Netherlands.

Alysia manducator mainly parasitizes larvae of calliphorid and sarcophagid flies which are commonly found at carcasses. It has a Palaearctic distribution but has also been introduced into other regions as biocontrol attempts (Wharton, 1986). We collected 54 adults from liver baits that were placed in the surroundings of our Institute at the town of Leiden.

\section{Detection of CSD and diploid males}

CSD can be detected with inbreeding studies by crossing relatives. In some species mother-son matings are possible because females can first reproduce as virgins and then be mated with one of their sons. The resulting progeny will only carry two sex alleles and half of the fertilized (diploid) eggs will be homozygous for the sex allele and develop into males (Fig. 1a). Note that there will also be males developing from unfertilized (haploid) eggs. If mother-son crosses are not possible, brothersister matings are used. Such crosses can be matched (two-allelic) or unmatched (three-allelic), depending on whether the son inherited the same or a different allele than the daughter (Fig. 1b). If both carry the same 
(a)

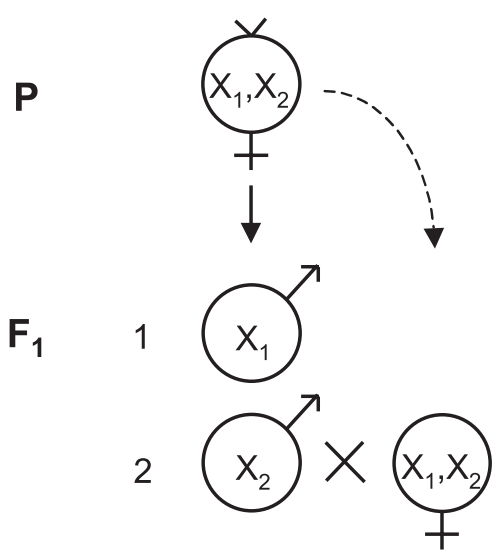

two matched matings

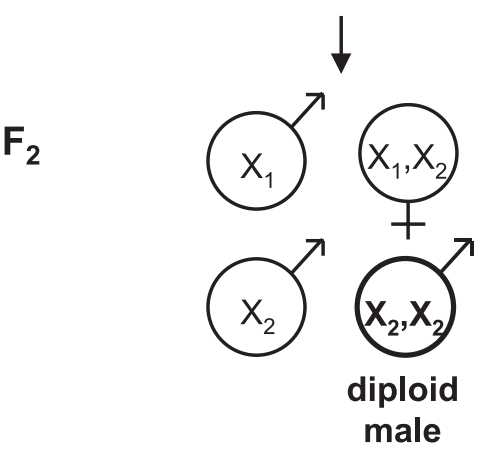

(b)

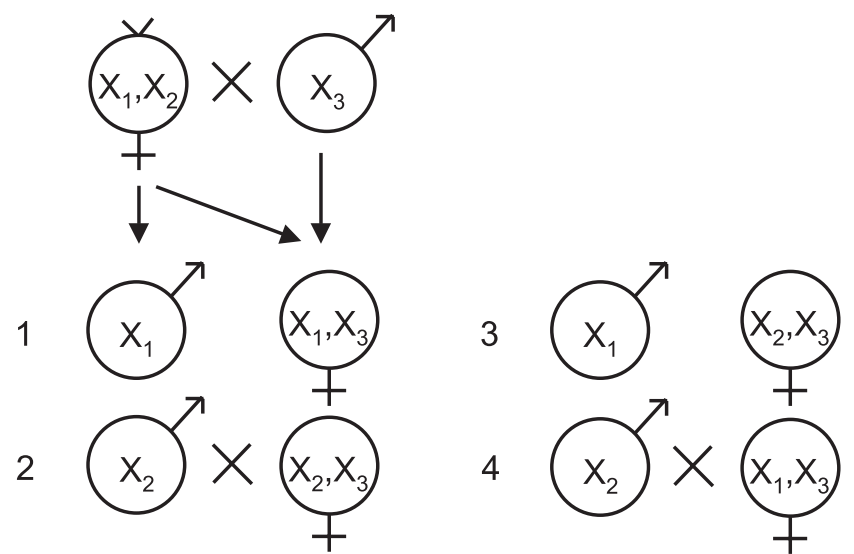

two matched matings

and
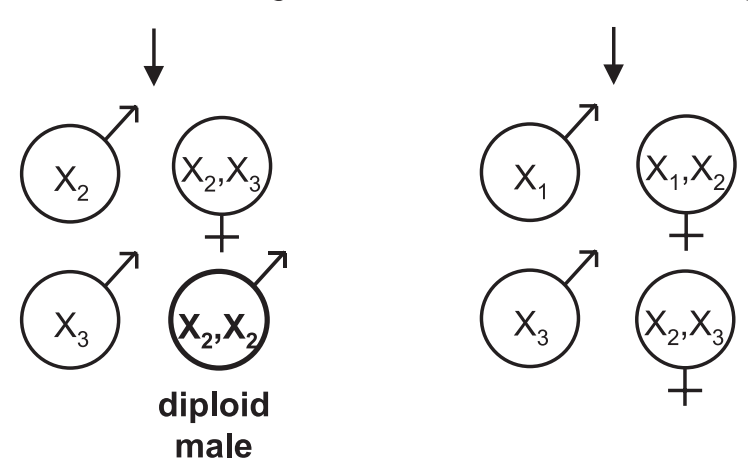

Fig. 1 Inbreeding crosses to detect single-locus complementary sex determination (sl-CSD). (a) Mother-son crosses. Diploid heterozygous females produce two types of hemizygous sons. In backcrosses with their mother, both types yield $50 \%$ diploid homozygous sons among fertilized eggs. Only $F_{2}$ offspring of the second possible $F_{1}$ cross are shown. (b) Brother-sister crosses. Diploid heterozygous females are mated with their hemizygous brothers. Two of these crosses are matched (two-allelic) and result in $50 \%$ diploid homozygous sons among fertilized eggs, whereas the other two combinations are unmatched (three-allelic) and do not result in diploid males. Only $\mathrm{F}_{2}$ offspring of the second and fourth possible $\mathrm{F}_{1}$ crosses are shown. On average, $25 \%$ of fertilized eggs are expected to become diploid males in brother-sister crosses.

allele, the diploid offspring will be $50 \%$ homozygous and male (similar to mother-son crosses), but if they carry different alleles $100 \%$ of diploid eggs will be heterozygous and female. Because half of brother-sister matings will by chance be matched and half will be unmatched, on average $25 \%$ of fertilized eggs are expected to become diploid males in such crosses. This will be manifested in an increase in the sex ratio of inbred crosses. However, because diploid males may be inviable, we also compared brood sizes and the number of nonemerged hosts in inbred and control crosses.

\section{Experimental set-up of Asobara tabida}

To obtain the inbred lines for the CSD experiments, 17 unmated females were each provided with 50-100 host larvae of D. subobscura in an agar-yeast suspension. After $24 \mathrm{~h}$ the females were transferred to separate tubes with an agar bottom and honey, and kept at $12^{\circ} \mathrm{C}$ to extend their lifespan. The parasitized larvae were kept at $19^{\circ} \mathrm{C}$. One son each of eight females was crossed back to its mother. Theoretically, diploid males could occur through inbreeding in half of the fertilized eggs in such crosses. However, no deviating sex ratios were found in the mother-son crosses. Six from the eight crosses yielded enough individuals to establish inbred lines for the experiments.

Three treatments, each comprising 24 replicates (four of each inbred line), were applied in the experiments: inbred related crosses, inbred control crosses and outbred control crosses. This means that inbred males of each line were mated three times: first, to an

(c) The Genetical Society of Great Britain, Heredity, 84, 29-36. 
(unrelated) inbred female from a different line; secondly, to his sister, an inbred female from the same line; thirdly, to an (unrelated) outbred female from the stock culture. The first cross was performed to have an independent measure for the effect of inbreeding on the sex ratio. This set-up allows a pairwise comparison of sex ratios. The mated females were each provided with 50-100 host larvae for $24 \mathrm{~h}$. The parasitized larvae were kept at $19^{\circ} \mathrm{C}$, which is the normal culturing temperature. After emergence, the numbers of males and females in the progeny of each female were counted to determine the brood size and sex ratio. After no more wasps emerged, the numbers of pupae and flies in each jar were counted and relative brood sizes were calculated as total number of wasps divided by total number of fly pupae. The experiment was repeated in the same way at $23^{\circ} \mathrm{C}$, which is the maximum culturing temperature for A. tabida.

\section{Experimental set-up of Alysia manducator}

Fifty-four adult females were collected from the field and individually placed onto $50-100$ hosts in $500 \mathrm{~mL}$ plastic containers. These females are referred to as 'fieldcollected'. Because these females had mated in the field and because females in this species do not survive until their offspring emerge, the $F_{1}$ offspring were used to set up inbred and control crosses. Hosts were larvae of Muscidae spp. that were bought from a fishing store. Inbred crosses consisted of a single son and daughter of one mother, i.e. they are brother-sister matings (Fig. 1b). Control crosses were matings of sons and daughters of different mothers. We typically set up twice as many inbred as control crosses because only half of the inbred crosses are expected to yield diploid males among fertilized eggs (see above).

The experiment was performed at $20^{\circ} \mathrm{C}$ and started with $\mathrm{F}_{1}$ offspring from 13 field-collected mothers, but later crosses also used $F_{2}$ offspring from the initial $F_{1}$ control crosses. In control crosses using $\mathrm{F}_{2}$ offspring we always made certain that we did not cross offspring from the same grandparents (field-collected females) to prevent the possibility of using two-allelic matings. After all progeny had emerged, which typically took up to 3 months at $20^{\circ} \mathrm{C}$, the numbers of pupae and flies were counted. The experiment was repeated in the same way at $23^{\circ} \mathrm{C}$ using offspring from 23 field-collected females. This maximum temperature was chosen after only one male wasp was found to emerge from 64 crosses at $25^{\circ} \mathrm{C}$.

\section{Statistical analysis}

Because CSD leads to an increase in sex ratio and a decrease in brood size (if diploid males are inviable) a comparison is made of brood sizes and sex ratios in inbred and control crosses. Numbers of progenies with fewer than 10 wasps did not differ between groups and were discarded because they disproportionately affect average sex ratios. Furthermore, all-male progenies were excluded from the analysis to prevent confusion of allmale progenies of virgin females with diploid male production under CSD. An exception forms the $23^{\circ} \mathrm{C}$ experiment of Alysia manducator where no progenies were excluded because brood sizes were very small because of the high temperature. The number of $<10$ wasp and all-male families was compared between groups with a chi-squared test.

Although randomized, not all experimental groups were provided with the same number of hosts (maximal difference $1.7 \times$ ), and therefore, relative brood sizes were estimated as number of wasps divided by number of hosts (= fly pupae). Sex ratios were estimated as number of males divided by total number of wasps. The variables sex ratio and relative brood size were both tested for normality using the Shapiro-Wilk test. If the variables differed significantly from a normal distribution, the variables were transformed using a logit transformation $\{\ln [p /(1-p)]\}$. The transformed data were analysed using a paired $t$-test, with the matings of an individual male as pairs (Asobara tabida), or an unpaired $t$-test (Alysia manducator). If variables still differed significantly from a normal distribution after transformation, they were analysed using a Wilcoxon matched pairs test.

A second method was used to test for the presence of CSD. The observed sex ratios in the inbreeding crosses were compared with the expected sex ratios under the assumption of CSD, both with viable diploid males and with inviable diploid males. The expected sex ratio with CSD is calculated from the fertilization proportion of the control crosses as:

( $W$ haploid males $+W$ diploid males $) / W$ total, if diploid males are viable;

$W$ haploid males/( $W$ total $W$ diploid males), if diploid males are inviable,

where $W$ is the number of wasps; for example, if the inbred crosses yielded a total of 1000 offspring and the fertilization proportion (sex ratio) of control crosses was $0.5,250$ fertilized eggs would be expected to develop into diploid males in the case of a two-allelic cross. This would result in a sex ratio of 0.75 if diploid males were viable and 0.67 if they were inviable. Deviations from the expected sex ratios were tested using a chi-squared test.

(c) The Genetical Society of Great Britain, Heredity, 84, 29-36. 


\section{Results}

\section{Asobara tabida}

In $A$. tabida males were crossed in succession to an unrelated inbred (ic), a related inbred (ir) and an outbred (oc) female at 19 and $23^{\circ} \mathrm{C}$. At $19^{\circ} \mathrm{C}$, the proportion of all-male progenies in the inbred related group was significantly larger than the inbred control group ( 6 vs. $1 \chi^{2}$-test: $P<0.001$ ), but not different from the outbred control group (6 vs. $5 \chi^{2}$-test: $P=0.615$ ). Figure 2 shows the relative brood sizes and sex ratios in the different treatments. No significant differences were found in relative brood sizes between the inbred related crosses and the inbred control crosses (paired $t$-test: $N=17$ progenies, $P=0.342$ ), nor between the inbred
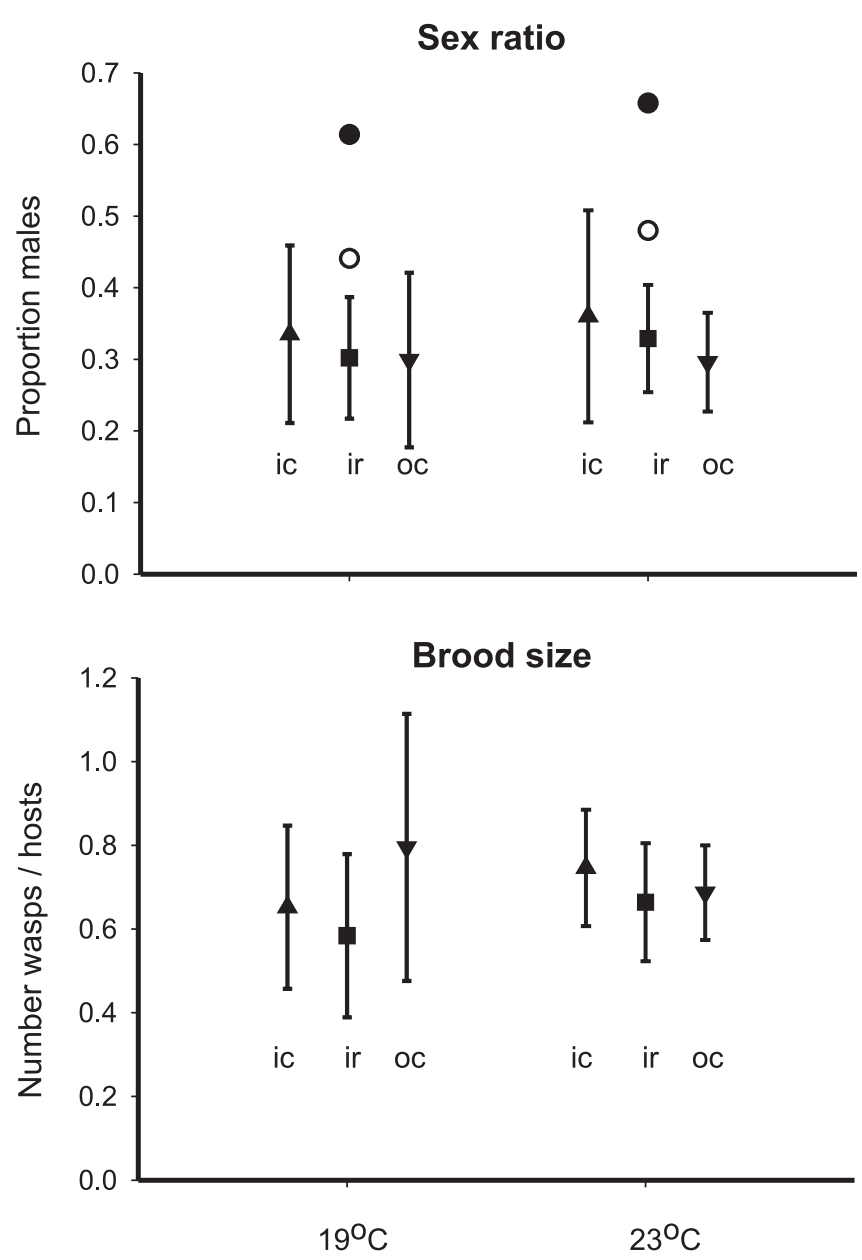

Fig. 2 Relative brood sizes and sex ratios of Asobara tabida at two temperatures. ic, inbred control; ir, inbred related; oc, outbred control. Expected sex ratios under single-locus complementary sex determination (sl-CSD) are given under the assumption of viable (solid circles) and inviable (open circles) diploid males. related crosses and the outbred control crosses (paired $t$-test: $N=15, P=0.059)$. Also, sex ratios did not differ significantly between treatments (paired $t$-test: ir vs. ic $N=17$ progenies, $P=0.329$; ir vs. oc $N=15, P=0.972$ ). The calculated expected sex ratio if CSD is present differs significantly from the sex ratio found in the inbred related treatment, under both the assumptions of viable males and inviable males $\left(\chi^{2}\right.$-test: both $P<0.001, N=864$ offspring).

Similar results were found at $23^{\circ} \mathrm{C}$ (Fig. 2). The proportion of all-male progenies did not differ between groups ( $\chi^{2}$-test: ir vs. ic, $P=1$; ir vs. oc, $\left.P=0.513\right)$. No significant differences were found in relative brood sizes between the inbred related crosses and the inbred control crosses (paired $t$-test: $N=16$ progenies, $P=0.163$ ), nor between the inbred related crosses and the outbred control crosses (paired $t$-test: $N=14$, $P=0.639)$. Sex ratios did not differ significantly between treatments (ir vs. ic, Wilcoxon: $N=16$ progenies, $P=0.959$; ir vs. oc, paired $t$-test: $N=14, P=0.515$ ). The calculated expected sex ratio if CSD is present differs significantly from the sex ratio found in the inbred related treatment, under both the assumptions of viable males and inviable males $\left(\chi^{2}\right.$-test: both $P<0.001, N=754$ offspring). These data show that sl-CSD does not occur in $A$. tabida.

\section{Alysia manducator}

In A. manducator, inbred and control crosses were performed among sons and daughters of field-collected females. Figure 3 shows the relative brood sizes and sex ratios for the different groups at 20 and $23^{\circ} \mathrm{C}$. At $20^{\circ} \mathrm{C}$, the numbers of all-male progenies were four, eight and two for field-collected (fc), inbred (i) and control (c) crosses, respectively ( $\chi^{2}$-test: i vs. fc, $P<0.715$; i vs. c, $P<0.038)$. No differences were found between brood sizes of field-collected, control and inbred crosses ( $t$-test: i vs. fc, $P=0.051$, d.f. $=42$; i vs. c, $P=0.254$, d.f. $=68$ ), nor in sex ratios ( $t$-test: i vs. fc, $P=0.263$, d.f. $=42$; i vs. c, $P=0.612$, d.f. $=68$ ). The calculated expected sex ratio if CSD is present differs significantly from the sex ratio found in the inbred treatment, under both the assumptions of viable males and inviable males $\left(\chi^{2}\right.$-test: both $P<0.001, N=1265$ offspring).

At $23^{\circ} \mathrm{C}$ brood sizes were on average $2.31 \pm 2.97 \mathrm{SD}$ and much smaller than $27.85 \pm 16.08 \mathrm{SD}$ at $20^{\circ} \mathrm{C}$. This is caused by high mortality among developing wasps at $23^{\circ} \mathrm{C}$ as shown by the high proportion of nonemerged hosts. Relative numbers of nonemerged hosts were on average 0.76 vs. 0.33 at $20^{\circ} \mathrm{C}$ and the relative numbers of emerging flies ( = nonparasitized hosts) was 0.19 vs. 0.24 , whereas in the absence of parasitism the proportions of flies that emerged were similar at 20 and $23^{\circ} \mathrm{C}$ 

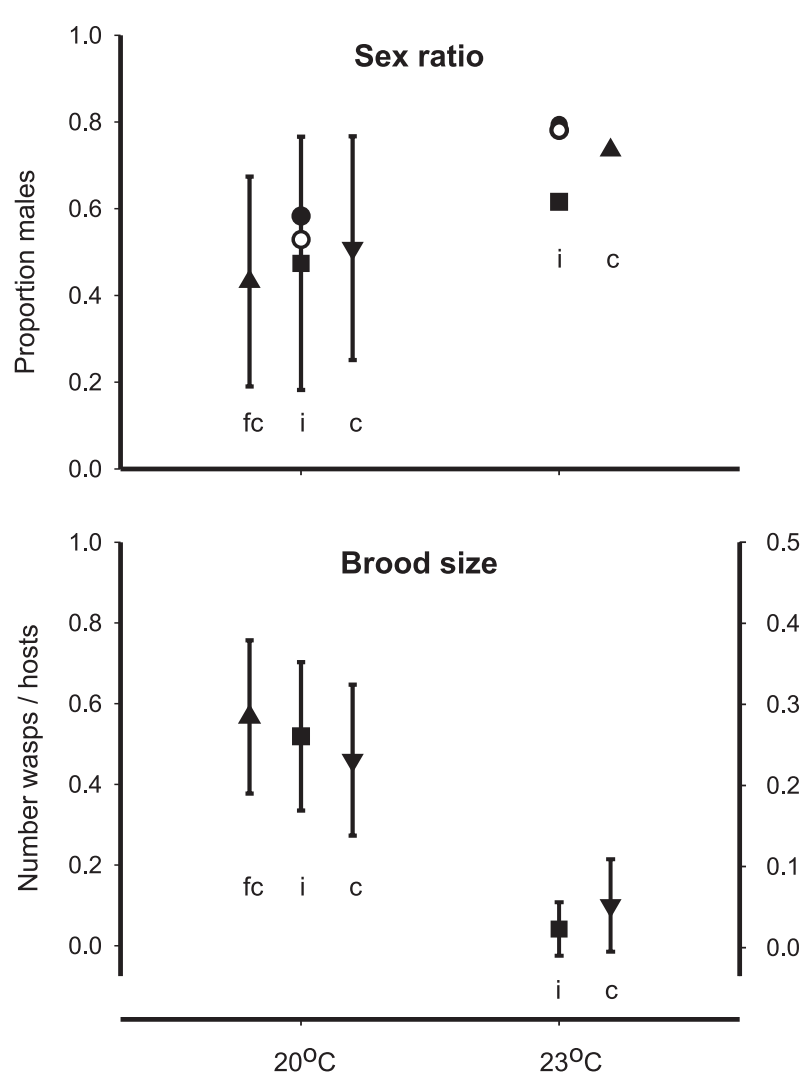

Fig. 3 Relative brood sizes and sex ratios of Alysia manducator at two temperatures. fc, field control; i, inbred; c, control. Expected sex ratios under single-locus complementary sex determination (sl-CSD) are given under the assumption of viable (solid circles) and inviable (open circles) diploid males. Note the different scaling of the $y$-axis in the brood size graph at $23^{\circ} \mathrm{C}$.

(93\%, $N=373$ and $95 \%, N=271$ pupae, respectively). Relative brood sizes were smaller in the control than inbred group ( $t$-test: i vs. c, $P=0.016$, d.f. $=85$ ). Because of the small brood sizes all offspring were pooled in each group to estimate an overall sex ratio. Overall sex ratios were higher in the control than inbred group, which is contrary to the expectations under CSD ( $\chi^{2}$-test: $P<0.001, N=167$ offspring). The calculated expected sex ratio if CSD is present differs significantly from the sex ratio found in the inbred treatment, under both the assumption of viable males and inviable males $\left(\chi^{2}\right.$-test: both $P<0.001, N=167$ offspring). These data are consistent with the absence of sl-CSD from $A$. manducator.

\section{Discussion}

The results show that inbreeding of Asobara tabida and Alysia manducator does not lead to diploid male production, and it can thus be concluded that sl-CSD is absent in these species. Because Butcher et al. (1998) reported that homozygous diploids in Venturia canescens and some Diadegma species developed into females at low $\left(<22^{\circ} \mathrm{C}\right)$ and into males at high $\left(>22^{\circ} \mathrm{C}\right)$ temperatures, experiments were performed at two temperatures, an optimum of 19 or $20^{\circ} \mathrm{C}$ and a maximum of $23^{\circ} \mathrm{C}$. We did not observe any difference in sex ratio at both temperatures in each species. Brood sizes of Alysia manducator, but not Asobara tabida, were reduced in the high temperature treatment. This was shown to be the result of high general mortality of wasps at $23^{\circ} \mathrm{C}$, rather than to be caused by differential mortality of diploid males. Therefore, there is no evidence for a temperature effect on sl-CSD in Asobara tabida and Alysia manducator. Obviously, we cannot exclude the theoretical possibility that a sl-CSD mechanism is present but never expressed in these two species, because they cannot be cultured at a permissible temperature. However, this would be biologically irrelevant.

Cook (1993a) draws attention to two points that need to be considered when performing inbreeding studies to test for CSD, rejection of multilocus CSD and the possibility of falsely rejecting CSD as a result of using highly inbred experimental populations as starting material. Multilocus CSD (Snell 1935; Crozier 1971) involves sex determination by two or more loci and homozygosity at all loci leading to diploid males. The speed at which complete homozygosity is reached under $\mathrm{ml-CSD}$ is lower than under sl-CSD. The proportion of diploid males in a system with $n$ loci each with two alleles will be $0.5^{n}$ (Cook 1993a). Until now, ml-CSD has only been explicitly tested and rejected in Nasonia vitripennis (Skinner \& Werren 1980) and Goniozus nephanditis (Cook 1993a). Cook could reject the presence of as many as 15 sex loci in G. nephanditis based on 22 generations of inbreeding. Although we have only inbred our species for one generation, we can statistically exclude the presence of two (but not more) loci from our Asobara tabida but not from the Alysia manducator data (calculations not shown). We cannot exclude that sex determination in our test species is based on multiple complementing alleles.

The second point of Cook (1993a) deals with the possibility of using experimental lines that already had reduced genetic variation. He presented a simple model based on a combination of sex ratio and mortality data that can be used as a quick initial test for the presence of single-locus two-allele CSD in any parasitoid species. In the absence of mortality, the primary sex ratio will always be male-biased when using a two-allelic cross because $50 \%$ of fertilized eggs will become diploid males, leading to a 0.5 sex ratio when fertilization is $100 \%$. Haploid males from unfertilized eggs will render the sex ratio more male-biased. A secondary femalebiased sex ratio is possible only if mortality occurs 
among diploid males. Because our species are solitary parasitoids, survival rates could easily be calculated from the number of nonemerged hosts in our control groups. Our Asobara tabida strain had been collected in the summer preceding our experiment and had been maintained in the laboratory for six generations. The control group (outbred control) had female-biased sex ratios (0.285) and survival of 0.742 , which exceeds Cook's critical value and rejects the single-locus twoallele sex-determining model for this species (cf. fig. 2 in Cook, 1993a). Our Alysia manducator experimental females $(N=13)$ were directly collected from the field, thus it is improbable that they all came from an inbred population with only two sex alleles because natural populations typically contain many alleles (Cook \& Crozier, 1995). The field-collected females produced a female-biased sex ratio $(0.430)$ and survival was 0.754 , which is slightly lower than Cook's critical value (0.877) and cannot exclude the single-locus two-allele model. However, we consider it unlikely that this is caused by mortality of diploid males. Cook's test is a one-way test and it cannot establish the presence of diploid males. One of the most plausible reasons for not complying with it, is that the laboratory conditions were suboptimal for the field-collected Alysia manducator females, leading to some mortality of parasitized fly pupae. Survival rates of parasitoids are typically not $100 \%$ (e.g. Godfray, 1994; Kraaijeveld \& van der Wel, 1994; Quicke, 1997) and the survival rate of Alysia manducator is similar to Asobara tabida in our experiments.

A sl-CSD mechanism of sex determination poses a burden on a population because diploid males are typically sterile and sometimes inviable (Whiting, 1943; Cook \& Crozier, 1995) and therefore slow down population growth. Because inbreeding increases the chance of matched matings and resulting diploid males, selection will most strongly favour loss of sl-CSD among naturally inbreeding species. Indeed, there is a strong negative correlation between the occurrence of inbreeding and CSD (Cook \& Crozier, 1995). Both Asobara tabida and Alysia manducator are solitary parasitoids. Asobara tabida breeds in sap fluxes and fruits with highly aggregated hosts. Such an ephemeral, patchy host distribution and the observed female-biased sex ratios (Hardy \& Godfray, 1990; Kraaijeveld \& Van Alphen, 1995; J. Ellers, unpublished observation) indicate a local mating structure. Absence of sl-CSD from Asobara tabida is therefore consistent with these observations. However, caution should be exercised when linking host distribution and sex allocation to mating structure. Antolin \& Strand (1992) showed that sib mating occurs rarely in Bracon hebetor even though it produces female-biased sex ratios. Both sexes were shown to disperse from the site of emergence before mating. Alysia manducator parasitizes mainly calliphorid flies (Wharton, 1986) that occur at carcasses. Very little is known about its mating structure and field sex ratios. Carcasses have a patchy distribution and some degree of local mating structure may therefore also be expected for this species depending on the degree of synchronous emergence and mating behaviour. However, the available information is insufficient to draw conclusions about selection against a sl-CSD mechanism in this species.

Asobara tabida and Alysia manducator both belong to the subfamily Braconinae and are the first members of the family Braconidae to be shown to lack sl-CSD. Thus far, all four tested species in this family, three species of Braconinae (Whiting \& Whiting, 1925; Speicher \& Speicher, 1940; Whiting, 1943; Clark \& Rubin, 1961) and one Microgasterinae (Steiner \& Teig, 1989), were found to have sl-CSD. Complementary sex determining has been suggested as the ancestral mode of sex determination in Hymenoptera (Schmieder \& Whiting, 1947; Crozier, 1977; Cook, 1993b) and is also believed to be the original mode in the Braconidae. In this respect, it is of interest to consider the phylogeny of the family. According to Van Achterberg (1993) the Microgasterinae is one of the most derived subfamilies, whereas the Braconinae is more ancestral to the Alysiinae. If we accept this phylogeny as valid, absence of CSD in the Alysiinae can be considered as a secondarily derived character. To resolve further the issue of ancestry of CSD among Braconidae members of more subfamilies need to be tested. In particular, it would be interesting to see whether the presumed oldest subfamilies such as the Rhyssalinae and Histeromerinae have sl-CSD.

\section{Acknowledgements}

We thank Cees van Achterberg for verifying the species identity of Alysia manducator, Heather Beaird and Reyhan Özkan for technical assistance and Marianne van Dijken and Tim Sharbel for comments on the manuscript. This work has been made possible by a fellowship of the Royal Netherlands Academy of Arts and Sciences to L.W.B.

\section{References}

ANTOLIN, M. F. AND STRAND, M. R. 1992. Mating system of Bracon hebetor (Hymenoptera: Braconidae). Ecol. Entomol., 17, 1-7.

BeUKeboom, L. w. 1995. Sex determination in Hymenoptera: a need for genetic and molecular studies. Bioessays, 17, 813-817.

BULl, J. J. 1983. The Evolution of Sex Determining Mechanisms. Benjamin/Cummings, Menlo Park, CA.

BUTCHER, R. D. J., WHITFIELD, W. G. F. AND HUBBARD, S. F. 1998. Temperature dependent single-locus complementary sex 
determination in Hymenoptera. In: Brunnhofer, V. and Soldán, T. (eds) Proc. 6th Eur. Congr. Entomol., p. 161. Ceské Budejovice, Czech Republic.

CLARK, A. M. AND RUBIN, M. A. 1961. The modification by X-radiation of the life span of haploids and diploids of the wasp, Habrobracon sp. Radiation Res., 15, 244-253.

COOK, J. M. 1993a. Empirical tests of sex determination in Goniozus nephanditis (Hymenoptera: Bethylidae). Heredity, 71, 130-137.

COOK, J. M. 1993b. Sex determination in the Hymenoptera: a review of models and evidence. Heredity, 71, 421-435.

COOK, J. M. AND CROZIER, R. H. 1995. Sex determination and population biology in the Hymenoptera. Trends Ecol. Evol., 10, 281-286.

CROZIER, R. H. 1971. Heterozygosity and sex determination in haplodiploidy. Am. Nat., 105, 399-412.

CROzIER, R. H. 1975. Hymenoptera. In: John, B. (ed.) Animal Cytogenetics 3, Insecta 7, pp. 1-95. Gebr. Borntraeger, Berlin.

CROZIER, R. H. 1977. Evolutionary genetics of the Hymenoptera. Ann. Rev. Ent., 22, 263-288.

DÜBENDORFER, A., HILFIKER-KLEINER, D. AND NÖTHIGER, R. 1992. Sex determining mechanisms in dipteran insects: the case of Musca domestica. Sem. Dev. Biol., 3, 349-356.

GAUld, I. AND BOLTON, B. 1996. The Hymenoptera. Oxford University Press, Oxford.

GODFrAy, H. C. J. 1994. Parasitoids: Behaviour and Evolutionary Ecology. Princeton University Press, Princeton, NJ.

HARDY, I. C. W. 1994. Sex ratio and mating structure in the parasitoid Hymenoptera. Oikos, 69, 3-20.

HARDY, I. C. W. AND GODFRAY, H. C. J. 1990. Estimating the frequency of constrained sex allocation in field populations of Hymenoptera. Behaviour, 114, 137-147.

HoDGKIN, J. 1990. Sex determination compared in Drosophila and Caenorhabditis. Nature, 344, 721-728.

HUGHES-SCHRADER, S. 1948. Cytology of coccids (Coccoidea: Homoptera). Adv. Genet., 2, 127-203.

KRAAIJEVELD, A. R. AND VAN ALPHEN, J. J. M. 1995. Variation in diapause and sex ratio in the parasitoid Asobara tabida. Entomologia. exp. appl., 74, 259-265.

KRAAIJEVELD, A. R. AND VAN DER WEL, N. N. 1994. Geographic variation in reproductive success of the parasitoid Asobara tabida in larvae of several Drosophila species. Ecol. Entomol., 19, 221-229.

METZ, C. w. 1938. Chromosome behavior, inheritance and sex determination in Sciara. Am. Nat., 72, 485-520.

NÖTHIGER, R. AND STEINMANN-ZWICKY, M. 1985. A single principle for sex determination in insects. Cold Spring Harb. Symp. Quant. Biol., 50, 615-621.
NUR, U. 1989. Reproductive biology and genetics. Chromosomes, sex ratios, and sex determination. In: Rosen, D. (ed.) Armoured Scale Insects, Their Biology, Natural Enemies and Control., vol. A, pp. 179-190. Elsevier Science Publishers, Amsterdam, The Netherlands.

PERIQUET, G., HEDDERWICK, M. P., EL AGOZE, M. AND POIRIÉ, M. 1993. Sex determination in the hymenopteran Diadromus pulchellus (Ichneumonidae): validation of the one-locus multi-allele model. Heredity, 70, 420-427.

QuiCKe, D. L. J. 1997. Parasitic Wasps. Chapman \& Hall, London.

ROSS, K. G., VARGO, E. L., KEller, L. AND TRAGER, J. C. 1993. Effect of a founder event on variation in the genetic sex-determining system of the fire ant, Solenopsis invicta. Genetics, 135, 843-854.

SANCHEZ, L. AND PERONDINI, A. L. P. 1999. Sex determination in sciarid flies: a model for the control of differential X-chromosome elimination. J. Theor. Biol., 197, 247-259.

SCHMIEDER, R. G. AND WHITING, P. W. 1947. Reproductive economy in the chalcidoid wasp Melittobia. Genetics, 32, $29-37$.

SKINNER, S. W. AND WERrEN, J. H. 1980. The genetics of sex determination in Nasonia vitripennis (Hymenoptera, Pteromalidae). Genetics, 94, s98.

SNELL, G. D. 1935. The determination of sex in Habrobracon. Proc. Natl. Acad. Sci. U.S.A., 21, 446-453.

SPEICHER, B. R. AND SPEICHER, K. G. 1940. The occurrence of diploid males in Habrobracon brevicornis. Am. Nat., 74, 379-382.

STEINER, W. W. M. AND TEIG, D. A. 1989. Microplitis croceipes: genetic characterisation and developing insecticide resistant biotypes. Southwest Entomol., 12, 71-87.

STOUTHAMER, R., LUCK, R. F. AND WERREN, J. H. 1992. Genetics of sex determination and the improvement of biological control using parasitoids. Ann. Entomol. Soc. Am., 21, 427-435.

SUOMAlAineN, E., SAURA, A. AND LOKKI, J. 1987. Cytology and Evolution in Parthenogenesis. CRC Press, Boca Raton, FL.

VAN ACHTERBERG, C. 1993. Illustrated key to the subfamilies of the Braconidae (Hymenoptera: Ichneumonidae). Zool. Verh., 283, 1-189.

WhARton, R. A. 1986. The braconid genus Alysia (Hymenoptera): a description of the subgenera and a revision of the genus Alysia. Syst. Entomol., 11, 453-504.

Whiting, P. W. 1939. Sex determination and reproductive economy in Habrobracon. Genetics, 28, 365-382.

WHITING, P. w. 1943. Multiple alleles in complementary sex determination of Habrobracon. Genetics, 28, 365-382.

Whiting, P. W. AND Whiting, A. R. 1925. Diploid males from fertilized eggs in Hymenoptera. Science, 62, 437-438. 